AGRITECH, Vol. 37, No. 1, Februari 2017, Hal. 77-80 DOI: http://dx.doi.org/10.22146/agritech.10669 ISSN 0216-0455 (Print), ISSN 2527-3825 (Online) Tersedia online di https://jurnal.ugm.ac.id/agritech/

\title{
Structural Changes in Cooked Rice Treated with Cooling-Reheating Process and Coconut Milk Addition as Observed With FT-IR and ${ }^{13} \mathrm{C}$ NMR
}

\author{
Nuri Arum Anugrahati', Yudi Pranoto², Yustinus Marsono², Djagal Wiseso Marseno² \\ ${ }^{1}$ Department of Food Technology, Faculty of Science and Technology, Pelita Harapan University, M.H. Thamrin Boulevard, \\ Lippo Karawaci, Tangerang, Banten 15811, Indonesia \\ ${ }^{2}$ Department of Food and Agricultural Product Technology, Faculty of Agricultural Technology, Universitas Gadjah Mada, \\ Jl. Flora No. 1, Bulaksumur, Yogyakarta 55281, Indonesia \\ Email: nuri.anugrahati@uph.edu
}

Submisi: 23 Januari 2016; Penerimaan: 25 April 2016

\begin{abstract}
The molecular structural changes of food could be observed by the technique of FT-IR and ${ }^{13} \mathrm{C}$ NMR spectroscopy. This research was aimed to study the structural changes in cooked rice treated with cooling-reheating process and coconut milk addition using FT-IR and ${ }^{13} \mathrm{C}$ NMR. It was found that the cooling-reheating process and addition of coconut milk cause several structural changes of cooked rice. The IR analysis showed the bands at 3,400, 2,900, 1,018 and $856 \mathrm{~cm}^{-1}$ changed due to the retrogradation during cooling process. The spectrum of ${ }^{13} \mathrm{C}$ NMR showed the change of peaks at 100.28 and $100.10 \mathrm{ppm}$. These changes may be related to the addition of coconut milk during rice cooking.
\end{abstract}

Keywords: Coconut milk; cooked rice; spectroscopic method

\section{INTRODUCTION}

As a staple food of Indonesian people, rice was often mixed and cooked with other ingredients, such as coconut milk and pandan leaves. The addition of those ingredients aimed to give a unique taste and aroma for the cooked rice.

Previous studies showed that the physicochemical changes of rice during processing affects the functional properties of the cooked rice. During rice cooking, the gelatinization process was occurred and gives the starch was easily digestible. The in vitro digestion rate was increase with longer amylose branches (Patindol et al., 2010) and smaller ratios of long amylopectin and long amylose branches to short amylopectin branches (Syahariza et al., 2013). On the other hand, the in vitro digestion rate was decrease with retrograded starch (Frei et al., 2003; Chung et al., 2006; Vatanasuchart et al., 2009).

The molecular structural changes of starch could be observed with several techniques, such as differential scanning calorimetry (DSC) (Sodhi and Singh, 2003), X-ray diffractions (XRD) (Zhu et al., 2011), Fourier transform infrared (FT-IR) (Falade et al., 2014), Raman (FT-Raman)
(Flores-Morales et al., 2012) and ${ }^{13} \mathrm{C}$ CP-MAS/NMR nuclear magnetic resonance (Zabar et al., 2009). The structural change of retrograded starch have been identified by the IR spectra on the band at $1,047 \mathrm{~cm}^{-1}$ while the band at $1,743 \mathrm{~cm}^{-1}$ associated to lipid and protein groups (Thygesen et al., 2003). Furthermore, amylose-lipid complexes could be identified from the NMR spectra. The fatty acids were trapped to both the acid form $(\mathrm{COOH})$ and the salt form $\left(\mathrm{COO}^{-}\right)$as can be inferred from the appearance of two signals at $177 \mathrm{ppm}$ and 182 ppm (Zabar et al., 2009).

In this research, the techniques of the FT-IR and ${ }^{13} \mathrm{C}$ NMR were used to observe the structural changes of cooked rice mixed with coconut milk. The mixture rice and coconut milk were observed in fresh and treated with cooling and reheating process.

\section{RESEARCH METHODS}

\section{Materials}

The rice sample known as Setra ramos variety and purchased from local market in Yogyakarta, Indonesia. This 
variety was chosen because of its amylose content (23.69 $\%)$ and resistant starch content $(21.13 \%)$. The commercial coconut milk fluid was purchased from market in Yogyakarta, Indonesia.

\section{Preparation of Mixture of Rice and Coconut Milk}

The preparation was done according to the method of Chung et al. (2006) and Rewthong et al. (2011) with modifications. Raw rice (100 g) was cooked with a 1.6 fold addition (w/v) of water and $50 \mathrm{~mL}(\mathrm{w} / \mathrm{v})$ of coconut milk using home-style rice cooker until automatic shutoff (about $20 \mathrm{~min}$ ). Fresh cooked rice samples were allowed to cool at room temperature for $15 \mathrm{~min}$ prior to analyses. The cooling and reheating process were treated to cooked rice samples for once and two times. The same procedure was done for cooked rice samples without addition of coconut milk.

\section{FT-IR Measurements}

The FT-IR measurements were done using the method of Falade et al. (2014). Samples ( $2 \mathrm{mg}$, dry basis) were mixed with $200 \mathrm{mg}$ anhydrous $\mathrm{KBr}$ and pressed using a manual press for $20 \mathrm{~min}$. Then, the pellets were transferred into FT-IR system. FT-IR spectra were recorded using a FT-IR Prestige 21 (Shimadzu Inc. USA). Each spectrum was recorded at a resolution of $4 \mathrm{~cm}^{-1}$ in a range $500-4,000 \mathrm{~cm}^{-1}$.

\section{${ }^{13}$ C NMR Measurements}

The ${ }^{13} \mathrm{C}$ NMR measurements were done according the method of Ai et al. (2013). Samples (10 mg, dry basis) were dissolved in 0.6-0.7 $\mathrm{mL}$ dimethyl sulfoxide. Then, the mixture was transferred into ${ }^{13} \mathrm{C}$ NMR system. The ${ }^{13} \mathrm{C}$ NMR spectra were recorded using ${ }^{13} \mathrm{C}$ NMR JEOL ECA-500 (USA). Each spectrum was recorded at room temperature at $500 \mathrm{mHz}$.

\section{RESULTS AND DISCUSSION}

The IR spectra of cooked rice treated with cooling and reheating process in Figure 1 showed identical characteristic bands among the treatments. The band at $3,400 \mathrm{~cm}^{-1}$ associated with - $\mathrm{OH}$ and the amplitude in the band changed with cooling and reheating process. The change of amplitude band was more pronounced for cooked rice treated with cooling and reheating process two times. Other change of characteristic band after cooling and reheating process was observed at $2,900 \mathrm{~cm}^{-1}$. The cooling process could increase the intensity of crystalline matrix in retrograded rice. These findings agreed with Park et al. (2009) who reported that the retrogradation phenomenon was due to temperature conditions $4{ }^{\circ} \mathrm{C}$. In addition, Flores-Morales et al. (2012) reported the changes of characteristic bands at 3,400 and $2,900 \mathrm{~cm}^{-1}$ were due to the phenomenon of retrogradation.

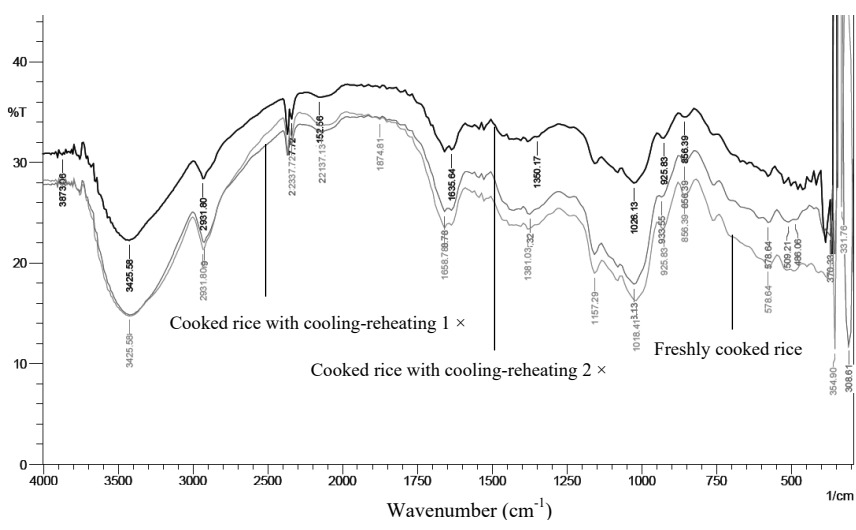

Figure 1. IR spectrum of cooked rice treated with cooling and reheating process

The bands at 1,018 and $856 \mathrm{~cm}^{-1}$ were also changed with the cooling and reheating process. These bands were more pronounced in the sample of cooked rice treated with cooling and reheating process two times than in the sample of freshly cooked rice and cooked rice with cooling and reheating process once time (Figure 1). Similar results were reported in previous studies. The region between 1,022 and $856 \mathrm{~cm}^{-1}$ were sensitive to changes in crystallinity and could be changed with retrogradation process (Falade et al., 2014; Falade and Christopher, 2015).

The peak at $1,743 \mathrm{~cm}^{-1}$ shown in the sample of cooked rice treated with cooling-reheating process and coconut milk addition (Figure 2). This result indicated the presence of lipid from coconut milk may form complex with the starch of cooked rice. The major component of coconut milk was lipid and the percentage of this lipid was varied between 15 and $40 \%$ (Simuang et al., 2004; Narataruksa et al., 2010). Flores-Morales et al. (2012) reported that the band at 1,743 $\mathrm{cm}^{-1}$ was identified as the ester carbonyl group. Thygesen et al. (2003) and Derycke et al. (2005) reported that the amylose could form complex with the lipids.

The bands at 1,635, 1,373 and 1,242 $\mathrm{cm}^{-1}$ also changed due to retrogradation in the sample with coconut milk addition (Figure 2). These findings were consistent with Thygesen et al. (2003) and García-Rosas et al. (2009) who reported the changes of these bands due to retrogradation.

The signals that appear in the ${ }^{13} \mathrm{C}$ NMR spectra for freshly cooked rice and cooked rice treated with coolingreheating process were similar (Figure 3 ). The peak at 99.79$99.81 \mathrm{ppm}$ is identified for $\mathrm{C}-1,71.39-73.01 \mathrm{ppm}$ for $\mathrm{C}-2$, C-3 and C-5, 78.65-78.68 ppm for C-4 and 60.37-60.40 ppm for $\mathrm{C}-6$ of the glucose of starch. The spectrum of cooked rice treated with cooling-reheating process showed a decreased peak corresponding to $\mathrm{C}-1, \mathrm{C}-2, \mathrm{C}-3, \mathrm{C}-4$ and $\mathrm{C}-5$. These findings supported by Flores-Morales et al. (2012) who 


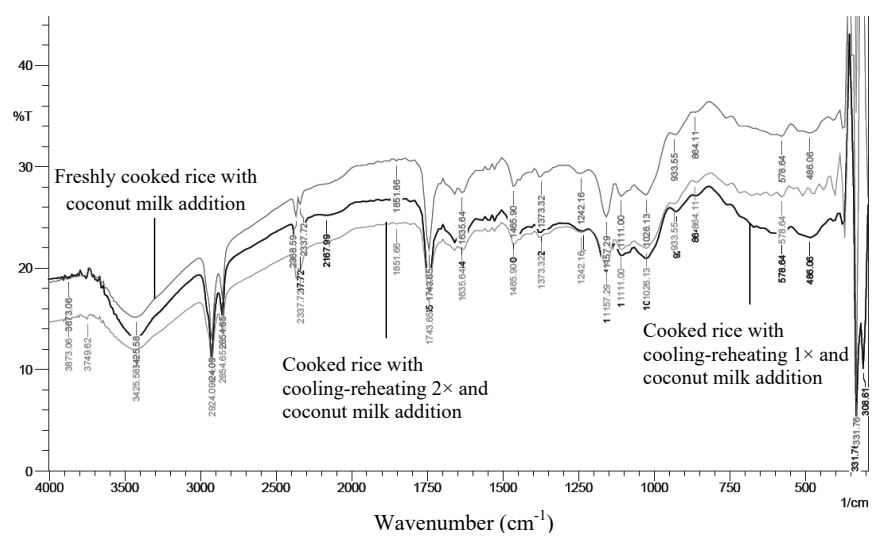

Figure 2. IR spectrum of cooked rice treated with cooling-reheating process and coconut milk addition

reported carbon chemical shift for starch has been identified in 101-106 ppm for C-1, in 72-76 ppm for C-2, C-3 and C-5, in 81-85 ppm for C-4 and in 62 ppm for C-6. Furthermore, as a comparison the retrograded of stored tortilla starch presents the additional peaks in C-1, the deformation peaks in C-6 and a decreased peak in C-2, C-3 and C-5.

The addition of coconut milk in cooked rice treated with cooling-reheating process once time gave a further decreased peak compared to freshly cooked rice without coconut milk addition (Figure 4). When cooling-and reheating process repeated two times in cooked rice with addition of coconut
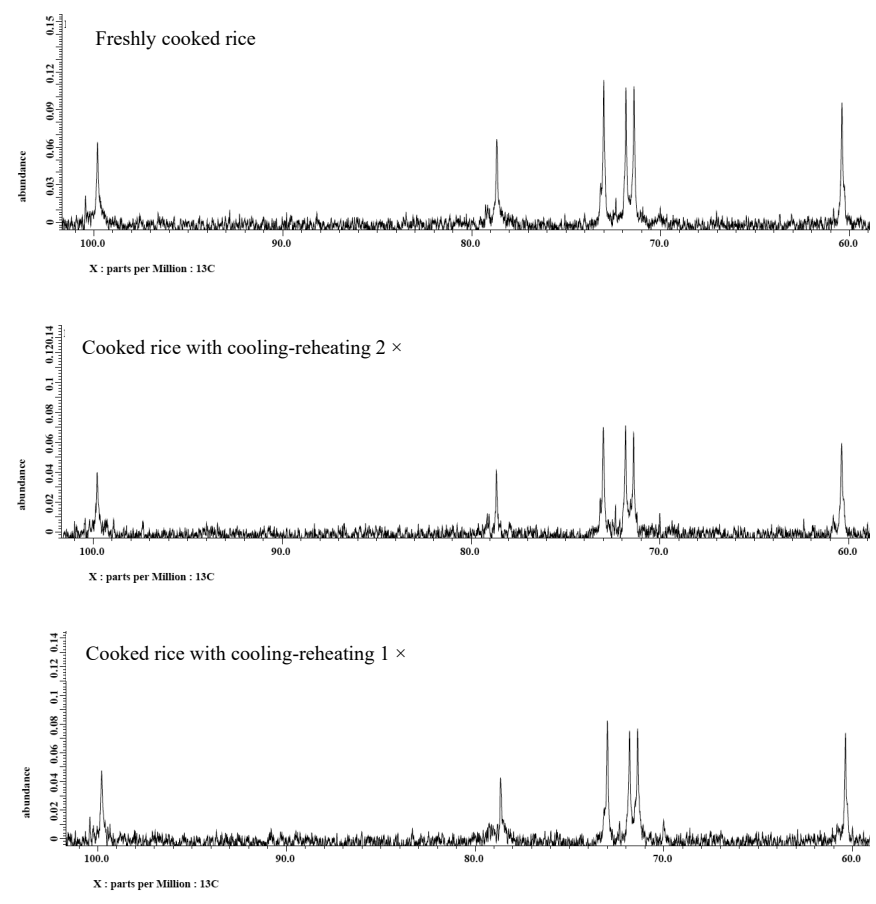

Figure 3. ${ }^{13} \mathrm{C}$ NMR spectrum of cooked rice treated with cooling and reheating process
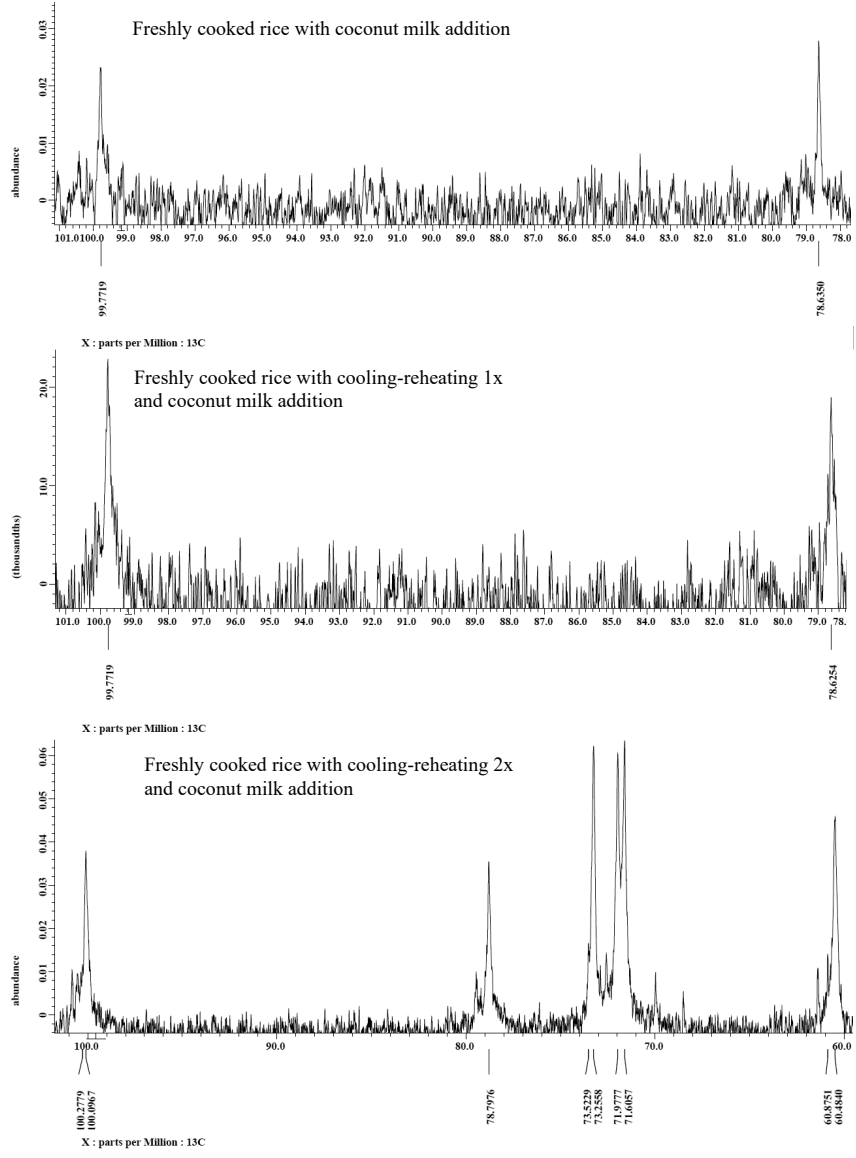

Figure 4. ${ }^{13} \mathrm{C}$ NMR spectrum of cooked rice treated with coolingreheating process and coconut milk addition

milk, the peak showed increase and C-1 resonance exhibit: two peaks at 100.28 and $100.10 \mathrm{ppm}$.

This result indicated that the addition of coconut mill could change the C-1 resonance. Primo-Martin et al. (2007) reported that the crystallinity and double helix symmetry of starch could be detected from multiplicity of the $\mathrm{C}-1$ position of the glucose units. In addition Ai et al. (2013) reported that the formation of starch helical complex with lipids caused the downfield changes in the chemical shifts of C-1 and C-4 of the amylodextrin.

\section{CONCLUSION}

The technique of FT-IR and ${ }^{13} \mathrm{C}$ NMR spectroscopy showed structural changes in cooked rice treated with coolingreheating process and coconut milk addition. The change of the band at 3,400 and 2,900 $\mathrm{cm}^{-1}$ indicated to retrogradation in cooked rice treated with cooling and reheating process. The peaks observed at 100.28 and $100.10 \mathrm{ppm}$ indicate that the structural changes of C-1 position of the glucose units due to the addition of coconut milk in cooked rice treated with cooling-reheating process. 


\section{REFERENCES}

Ai, Y., Hasjim, J. and Jane, J.-L. (2013). Effects of lipids on enzymatic hydrolysis and physical properties of starch. Carbohydrate Polymers 92: 120-127.

Chung, H.-J., Lim, H.S. and Lim, S.-T. (2006). Effect of partial gelatinization and retrogradation on the enzymatic digestion of waxy rice starch. Journal of Cereal Science 43: 353-359.

Derycke, V., Vandeputte, G.E., Vermeylen, R., Man, W.D., Goderis, B., Koch, M.H.J. and Delcour, J.A. (2005). Starch gelatinization and amylose-lipid interactions during rice parboiling investigated by temperature resolved wide angle X-ray scattering and differential scanning calorimetry. Journal of Cereal Science 42: 334-343.

Falade, K.O., Semon, M., Fadairo, O.S., Oladunjoye, A.O. and Orou, K.K. (2014). Functional and physic-chemical properties of flours and starches of African rice cultivars. Food Hydrocolloids 39: 41-50.

Falade, K.O. and Christopher, A.S. (2015). Physical, functional, pasting and thermal properties of flours and starches of six Nigerian rice cultivars. Food Hydrocolloids 44: 478-490.

Flores-Morales, A., Jiménez-Estrada, M. and Mora-Escobedo, R. (2012). Determination of the structural changes by FT-IR, Raman, and CP/MAS ${ }^{13} \mathrm{C}$ NMR spectroscopy on retrograded starch of maize tortillas. Carbohydrate Polymers 87: 61-68.

Frei, M., Siddhuraju, P. and Becker, K. (2003). Studies on the in vitro starch digestibility and the glycemix index of six different indigenous rice cultivars from the Philippines. Food Chemistry 83: 395-402.

García-Rosas, M., Bello-Pérez, A., Yee-Madeira, H., Ramos, G., Flores-Morales, A. and Mora-Escobedo, R. (2009). Resistant starch content and structural changes in maize (Zea mays) tortillas during storage. Starch/Stärke 61: 414-421.

Narataruksa, P., Pichitvittayakarn, Heggs, P.J. and Tia, S. (2010). Fouling behavior of coconut milk at pasteurization temperatures. Applied Thermal Engineering 30: 1387-1395.

Park, E.Y., Baik. B.-K. and Lim, S.-T. (2009). Influences of temperature-cycled storage on retrogradation and in vitro digestibility of waxy maize starch. Journal of Cereal Science 50: 43-48.
Patindol, J., Guraya, H., Champagne, E., Chen, M.-H. and McClung, A. (2010). Relationship of cooked-rice nutritionally important starch fractions with other physicochemical properties. Starch/Stärke 62: 246-256.

Primo-Martin, C.N.H., Nieuwenhuijzen, V.R.J., Hamer, T. and Van Vliet. (2007). Crystallinity changes in wheat starch during the bread-making process: starch crystallinity in the bread crust. Journal of Cereal Science 45: 219-226.

Rewthong, O., Sopononnarit, S., Taechapairoj, C. and Tungtrakul, P. (2011). Effects of cooking, drying and pretreatment methods on texture and starch digestibility of instant rice. Journal of Food Engineering 103: 258264.

Simuang, J. Chiewchan, N. and Tansakul, A. (2004). Effects of fat content and temperature on the apparent viscosity of coconut milk. Journal of Food Engineering 64: 193197.

Sodhi, N.S. and Singh, N. (2003). Morphological, thermal and rheological properties of starches separated from rice cultivars grown in India. Food Chemistry 80: 99108.

Syahariza, Z.A., Sar, S., Hasjim, J., Tizzotti, M.J. and Gilbert, R.G. (2013). The importance of amylose and amylopectin fine structures for starch digestibility in cooked rice grains. Food Chemistry 136: 742-749.

Thygesen, L.G., LØkkey, E.M., Micklander, L. and Engelsen, O.B. (2003). Vibrational microspectroscopy food RAMAN vs FT-IR. Trends in Food Science and Technology 14: 50-57.

Vatanasuchart, N., Niyomwit, B. and Wongkrajang, K. (2009). Resistant starch contents and the in vitro starch digestibility of Thai starchy foods. Kasetsart Journal Natural Science 43: 178-186.

Zabar, S., Lesmes, U., Katz, I., Shimoni, E. and Bianco-Peled, H. (2009). Studying different dimensions of amyloselong chain fatty acid complexes: Molecular, nano and micro level characteristics. Food Hydrocolloids 23: 1918-1925.

Zhu, L.J., Liu, Q.Q., Wilson, J.D., Gu, M.M. and Shi, Y.C. (2011). Digestibility and physicochemical properties of rice (Oryza sativa L.) flours and starches differing in amylose content. Carbohydrate Polymers 86: 17511759. 